\title{
Forkhead box transcription factor 1 expression in gastric cancer: FOXM1 is a poor prognostic factor and mediates resistance to docetaxel
}

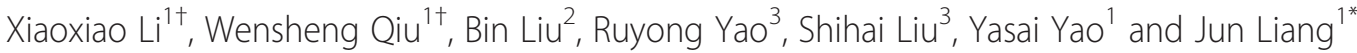

\begin{abstract}
Background: Forkhead box transcription factor 1 (FOXM1) has been reported to overexpress and correlate with pathogenesis in a variety of human malignancies. However, little research has been done to investigate its clinical significance in gastric cancer.

Methods: We examined the expression of FOXM1 in 103 postoperational gastric cancer tissues and 5 gastric cell lines by immunohistochemistry and western blot analysis respectively. Data on clinic-pathological features and relevant prognostic factors in these patients were then analyzed. Moreover, the association of FOXM1 expression and chemosensitivity to docetaxel in gastric cancer cells was further explored.

Results: Our study demonstrated that the level of FOXM1 expression was significantly higher in gastric cancer than in para-cancer tissues $(P<0.001)$ and normal gastric cell lines $(P=0.026)$. No significant association was found between FOXM1 expression and any clinical pathological features $(P>0.1)$. FOXM1 amplification was identified as an independent prognostic factor in gastric cancer $(P=0.001)$, and its affection is more significant in patients with tumor size larger than $5 \mathrm{~cm}(P=0.004)$, pT3-4 $(P=0.003)$ or plll-IV $(P=0.001)$. Additionally, shown to mediate docetaxel resistance in gastric cancers by our research, FOXM1 was revealed to alter microtubule dynamics in response to the treatment of docetaxel, and the drug resistance could be reversed with FOXM1 inhibitor thiostrepton treatment.
\end{abstract}

Conclusions: FOXM1 can be a useful marker for predicting patients' prognosis and monitoring docetaxel response, and might be a new therapeutic target in docetaxel resistant gastric cancer.

Keywords: FOXM1, Gastric cancer, Prognosis, Docetaxel resistance

\section{Background}

Despite the developments of surgical technique and improvements of anticancer drugs recently, gastric cancer is still the main cause of death and strongly associated with poor outcome. So far, in China, the morbidity of gastric cancer has reached to second with 3,621,000 new cases, whilst the mortality rate ranked third with the proportion of $14.33 \%$ each year [1]. Most patients present with metastatic or unresectable disease at the time of diagnosis [2]. For these surgically unfit but medically fit patients, palliative chemotherapy is the main

\footnotetext{
*Correspondence: ljqyfy@163.com

${ }^{\dagger}$ Equal contributors

'Department of Oncology, Affiliated Hospital of Medical College Qingdao University, 16 Jiangsu Road, Qingdao 266003, China

Full list of author information is available at the end of the article
}

choice of treatment. Among new generation chemotherapy regimens, docetaxel, which is a semisynthetic taxane, promoting the assembly and stabilization of microtubules to inhibit the depolymerization [3], has been used more and more extensively with potent effects [4-6]. The chemotherapy regimen of docetaxel, cisplatin and 5 -fluorouracil (DCF) has been commonly used to treat the advanced stage or metastatic gastric carcinoma with encouraging survival outcomes [7-12] and better quality of life $[13,14]$. Yet, resistance to docetaxel does occur in gastric cancers [15]. Thus, identification of some suitable biomarkers for predicting patient prognosis and chemosensitivity is significant for improving therapeutic effects for patients with advanced gastric cancer.

\section{Biomed Central}

(c) 2013 Li et al.; licensee BioMed Central Ltd. This is an Open Access article distributed under the terms of the Creative Commons Attribution License (http://creativecommons.org/licenses/by/2.0), which permits unrestricted use, distribution, and reproduction in any medium, provided the original work is properly cited. 
Forkhead box protein M1 (FOXM1), characterised by a 100 amino acid winged-helix DNA binding domain, is a newly unified family member of Forkhead transcription factor [16]. Previous researches indicated that FOXM1, activated by the Ras-MAPK and hedgehog signaling pathway $[17,18]$, played an important role in cell cycle by promoting both the transition from $\mathrm{G} 1$ to $\mathrm{S}$ phase and progression to mitosis through genes of Cdc25B, CDK1 and p27 ${ }^{\mathrm{KIP}}$ et al. $[19,20]$. It was demonstrated that FOXM1 overexpressed in gastric cancer and that elevated FOXM1 promoted tumor development in various kinds of cancers, correlated closely with poor outcome [21-23]. Additionally, in current research, FOXM1 amplification was reported to confer primary resistance of gefitinib in nonsmall cell lung cancer (NSCLC) and acquired paclitaxel resistance in breast cancer, showing implications in resistance to chemotherapy strongly $[24,25]$. These results suggested that FOXM1 may play an important role in progression of human cancers and may be associated with the resistance to docetaxel. Although FOXM1 has been revealed to mediate promotion of human gastric cancer angiogenesis, growth, and metastasis [26], the clinical significance of FOXM1 overexpression in gastric cancer is still little explored yet.

In current study, we examined the expression of FOXM1 protein in both gastric cancer specimens and cell lines, and assessed correlations among FOXM1 overexpression, clinic-pathological characteristics and clinic outcome. In addition, we investigated the relationship between overexpression of FOXM1 and docetaxel resistance in gastric cancer cells, trying to provide a support to its clinical significance in clinical practice.

\section{Materials and methods}

\section{Human tissue specimens and patient information}

Gastric cancer tissues were obtained from 103 patients who underwent gastrectomy and D2 lymphadenectomy at the Affiliated Hospital of Qingdao University Medical College from Jan 2007 to Nov 2007. 68 para-cancer tissues which were more than $5 \mathrm{~cm}$ away from the edge of tumor were randomly selected. All patients meet the criteria: 1) Tumors were confirmed to be gastric adenocarcinoma histologically. 2) None had received any preoperative treatment such as chemotherapy or radiotherapy. 3) Everyone was available of follow-up data. Clinic-pathological information was obtained from patient's operative and pathological reports, in which age ( $\leq 50$ years or $>50$ years), gender, size of tumor $(\leq 5 \mathrm{~cm}$ or $>5 \mathrm{~cm})$, depth of tumor invasion ( $\mathrm{T} 1$ : tumor has invaded the mucosa or submucosa layer; T2: tumor has invaded the muscular layer; T3: tumor has invaded subserosa; T4: tumor invaded serosa or adjacent organs), lymph node metastasis, degree of differentiation (undifferentiated or differentiated),venous invasion, neural invasion, Borrmann type (Borrmann I, II, III, IV),
Lauren type (intestinal, diffuse, mixed) and the 7th American Joint Committee on Cancer (AJCC) TNM stage (I, II, III, IV) were included.

\section{Cell lines and culture conditions}

Three gastric cancer cell lines, SGC-7901, AGS, and MKN-28 and two normal gastric epithelium cell lines, GES-1 and HFE-145 were obtained from the central laboratory of Affiliated Hospital of Qingdao University Medical College. All these five cell lines were cultured in RPMI 1640 (Thermo scientific, CA), supplemented with 10\% FBS (Thermo scientific, CA) and 1\% Penicillin/Streptomycin (Invitrogen, Tokyo, Japan), and incubated in $5 \% \mathrm{CO}_{2}$ at $37^{\circ} \mathrm{C}$. The semisynthetic taxane, docetaxel (Selleckchem, US), was dissolved in dimethyl sulfoxide (DMSO) and diluted to a final concentration of $0.015 \mathrm{mg} / \mathrm{L}$ and $0.020 \mathrm{mg} / \mathrm{L}$ before use.

\section{Immunohistochemistry}

The expression of FOXM1 was detected through immunohistochemistry (IHC) analyses with 3-um-thick sections of formalin-fixed and paraffin-embedded blocks. For IHC staining, tissue sections were dewaxed in xylene and rehydrated gradually with graded ethanol. For antigen retrieval, all the sections were incubated by microwave oven in citrate buffer solution ( $\mathrm{pH}$ 6.0) for 20 minutes. Endogenous peroxidase was inactived by $0.3 \%$ hydrogen peroxide in methanol for $15 \mathrm{~min}$. After that, tissue slides were incubated with rabbit polyclonal antibody against human FOXM1 (dilution 1:100, Epitomics, US) at $4^{\circ} \mathrm{C}$ overnight and then visualized antibody binding sites with the SP peroxidase detection system. Finally, sections were incubated in 3,3'diaminobenzidine tetrahydrochloride for 3-10 minutes and restained with $0.1 \%$ hematoxylin. In every case, negative control reaction was set with PBS replacing FOXM1 antibody, while the known positive-stained section was used as positive control. The results of IHC were evaluated by two pathologists independently with no knowledge of clinic-pathological features.

The expression of FOXM1 was scored by multiplying the intensity scores and the percentage area positively stained $[27,28]$. Briefly, the intensity score was categorized into four groups: no staining marked 0; weak staining marked 1; moderate staining marked 2 and strong staining marked 3. For the percentage of positively stained cells, the scores were sorted from 0 to 4 ( $<5 \%$ marked $0 ; 5 \%$ $25 \%$ marked 1; 25\%-50\% marked 2; 51\%-75\% marked 3; $75 \%$ marked 4). After such calculation, the finally composite scores were divided into four grades: 0-1 were negative, 2-4 were weakly positive, 5-8 were moderately positive and 9-12 were strongly positive. 2 and more than 2 scores were evaluated as positive results. 


\section{Western blot analysis}

Whole-cell lysates were prepared from gastric cancer cell lines which were in logarithmic growth phase or at indicated periods of time. Total proteins were fractionated using sodium dodecyl sulfate polyacrylamide gel electrophoresis and transferred onto Polyvinylidene fluoride membrane. Anti-FOXM1 (dilution 1:1000, Epitomics, US) and anti-GAPDH (dilution 1:2000, CWBIO, CA) rabbit polyclonal antibodies were used as primary antibodies. For tubulin fractionation, $\alpha$-tubulin antibody (1:1000, Santa, US) and $\beta$-tubulin antibody (1:1000, Santa, US) were used for analysis. The signals were detected using the VILBER enhanced chemiluminescence system (VILBER LOURMAT, FRA) according to the manufacturer's instructions. Results shown were derived from at least three independent experiments.

\section{MTT assay}

For MTT assays, 5000 cells were seeded overnight in 96well plates and then cultured in $100 \mu \mathrm{L}$ of fresh medium that contained various concentrations of docetaxel for 24-72 hours. Each concentration was repeated in triplicate. After that, MTT solution $(20 \mu \mathrm{L}, 5 \mathrm{mg} / \mathrm{mL}$ in PBS) was added to each well and the plate was incubated at $37^{\circ} \mathrm{C}$ for 4 hours. The solution was then removed and $200 \mu \mathrm{L}$ of DMSO was added to each well. After $10 \mathrm{mi}-$ nutes of vibration mixing, the optical density (OD) at $490 \mathrm{~nm}$ was measured using a microplate reader (Bio RAD, US).

\section{Plasmids and transfections}

The human FOXM1 expression vector pcDNA3.1-FOXM1 and siRNA-FOXM1 were obtained from the center library of Affiliated Hospital of Qingdao University Medical College. For transfections, cells were seeded to a $40-50 \%$ confluence state and transfected with pcDNA3.1-FOXM1, siRNA-FOXM1 or pcDNA3.1 with Lipofectamine 2000 agent (Invitrogen, US) in accordance with the manufacturer's protocol. After transfection, cells were cultured for $48 \mathrm{~h}$ and analyzed by western blotting and MTT assay.

\section{Semi-quantitative RT-PCR}

Total cellular RNA was extracted from cell pellets of each cell lines with Trizol reagent. The amount of RNA was determined by BJKO assay system (BJKO, CA), and part of them was reverse transcribed using the Reverse Transcription System (TaKaRa, CA). The primer sequences for PCR amplification were as follows: FOXM1 sense 5' - TAT TCA CAG CAT CAT CAC AGC A-3' and antisense $5^{\prime}$ - GAA GGC TCC TCA ACC TTA ACC T-3'; GAPDH sense 5'- ACC ACA GTC CTG CAT GCC AC -3' and antisense 5' - TCC ACC ACC CTG TTG CTG TA $-3^{\prime}$. To ensure experiment accuracy, all reactions were performed in triplicate. The integrity of all RNA samples was verified by RT-PCR for GAPDH in each sample through gel imaging systerm (VILBER LOURMAT, FRA). The value of FOXM1 expression was divided by that of GAPDH in each sample.

\section{Molecular evolution assay}

The gastric cancer cell line AGS was treated with $0.015 \mathrm{mg} / \mathrm{L}$ docetaxel for 72 hours when cells reached a confluency of $80 \%$. After treatment, docetaxel containing medium was replaced by fresh medium. As soon as cells recovered, they were seeded for RNA isolation, cell lysis (protein), MTT assays and the next treatment cycle. In this manner, several rounds of molecular evolution assay were performed. To obtain the appropriate rate of cell death in the molecular evolution assay, several docetaxel concentrations were tested in a preliminary experiment. Thereby, $0.015 \mathrm{mg} / \mathrm{L}$ was obtained as the most suitable concentration.

\section{Tubulin assay}

Separation of polymerized and soluble fractions was done in accordance with previously published assays [25]. Cells were seeded at $80 \%$ confluency in 24-well plates. The following day they were treated with 0 or $0.020 \mathrm{mg} / \mathrm{L}$ docetaxel for 48 hours. Cells were collected in hypotonic buffer $(1 \mathrm{mM} \mathrm{MgCl} 2,2 \mathrm{mM}$ EGTA, $0.5 \%$ Nonidet P-40, 20 mM Tris- $\mathrm{HCl}$ pH 6.8) and centrifuged for 10 minutes at room temperature $(14,000 \mathrm{rpm})$. The supernatant was used as the soluble fraction while the pellet made up the polymerized fraction. Samples were analyzed by western blot.

\section{Follow-up}

We performed a 5-year retrospective, cohort research for individual patients after gastric cancer surgery from 2007 to 2012. The median duration of follow-up was 49.2 months (range, 7-60 months). For patients who remained alive until the cut-off date, survival data were recorded as 60 months. The information about survival was collected in the Oncology Department of the Affiliated Hospital of Medical College Qingdao University. Also, informed consent was obtained from all the patients. The ethical committee of our institute approved the research protocol for this study.

\section{Statistical analysis}

We used Chi-Square statistical test to identify correlations in the human gastric cancer clinic-pathological parameters and Log-rank analysis for the in vivo (patients) survival study. In addition, we evaluated significant differences in vitro data using Student's t-test. A significance level set at $\mathrm{p}<0.05$ was considered significant for all the tests. 


\section{Results}

FOXM1 protein expression in gastric cancer tissues and cell lines

FOXM1 was positively stained in the nuclei or cytoplasm of $79 \%$ gastric cancer cells, whereas the paracancer tissues showed much lower levels of FOXM1 with nonspecific weak staining (11.8\%) (Figure 1A). Among the 103 gastric cancer specimens, 12 cases were detected as strongly positive for FOXM1 expression (12\%), 38 cases were moderately positive (37\%), 31 cases were weakly positive (30\%), and 22 cases were negative (21\%) (Table 1). When further investigate the relationship between FOXM1 expression and clinic-pathlogical features in these gastric cancer patients, no significant association was found between the expression of FOXM1 and any clinic-pathological parameters, even no tendency can be seen (Table $2, \mathrm{P}>0.1$ ). Overall, IHC results revealed that the level of FOXM1 expression was significantly higher in gastric cancer than in para-cancer tissues (Table $1, \mathrm{P}<0.001$ ), indicating that FOXM1 was commonly overexpressed in human gastric cancers.

To further confirm that results in vitro, we next investigated the level of FOXM1 expression in benign and malignant human gastric cell lines by western blot analysis. As a result, the gastric cancer cell lines equally exhibited 6-fold more FOXM1 expression compared with the normal ones (Figure 1B, $\mathrm{P}=0.026$ ), in which a homogenous FOXM1 expression was showed in the gastric epithelium cell lines such as GES-1 and HFE-145, whereas FOXM1 expression levels were more heterogeneous and in total elevated in cancerous cell lines, demonstrating that FOXM1 also overexpressed in human gastric cancer cell lines.

\section{Prognostic significance of FOXM1 expression in survival of gastric cancer patients}

The survival curves of patients after gastrectomy according to FOXM1 expression were showed in Figure 2A. The data demonstrated that 5-year survival rate was significantly lower in patients with positive FOXM1 expression than those without $(\mathrm{P}=0.030)$. Univariate analysis revealed that tumor size, $\mathrm{T}$ stage, lymph node metastasis, vascular invasion, FOXM1 expression, and TNM stage were associated with an inferior survival duration (Table 3, $\mathrm{P}<0.05)$. However, only the tumor size, $\mathrm{T}$ stage, FOXM1 expression and TNM stage were verified to be independent prognostic factors for the survival in gastric cancer patients after multivariate analysis (Table $3, \mathrm{P}<0.05$ ).

A

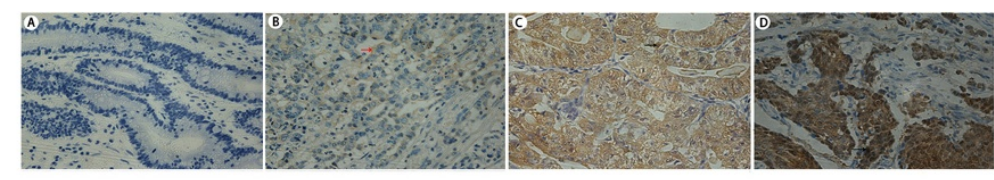

B
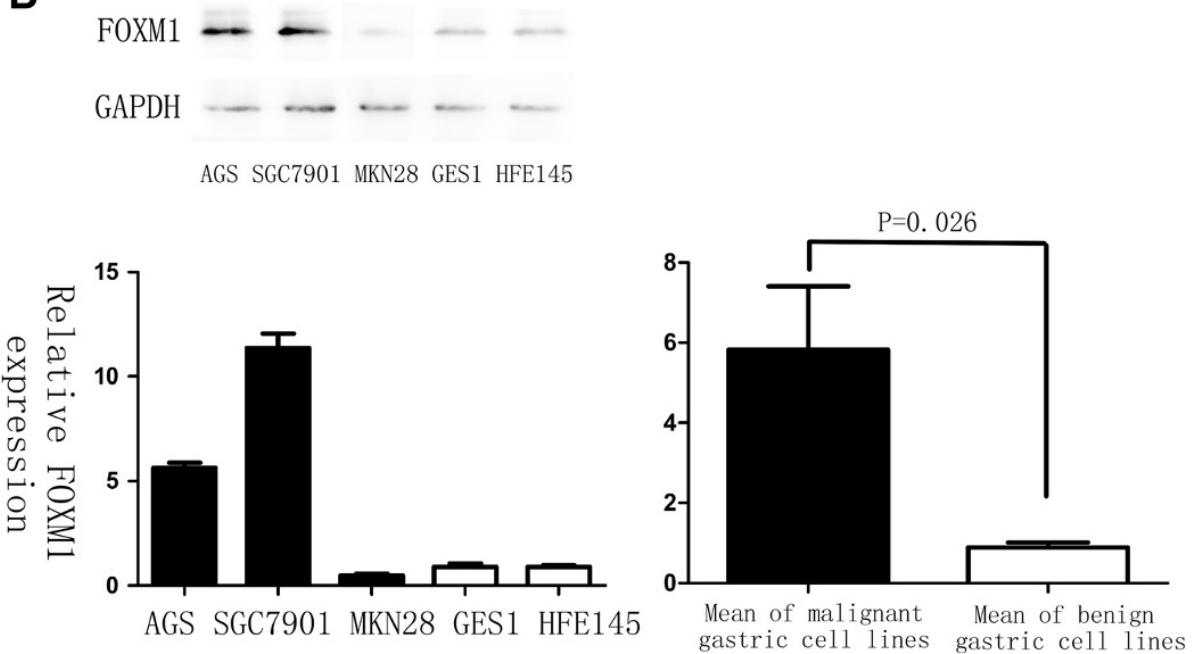

Figure 1 FOXM1 expression in gastric cancer tissues and cell lines. (A) Immunohistochemical staining for FOXM1 antibody in gastric cancer tissue: (A). Negative staining for FOXM1, ×400; (B). Weakly positive staining for FOXM1, ×400; (C). Moderately positive staining for FOXM1, ×400; (D). Strongly positive staining for FOXM1, $\times 400$. FOXM1 expression was stained in the nuclei or cytoplasm of cells. Red arrow: cytoplasm stained; Black arrow: nuclei stained. (B) Different expressions of FOXM1 in gastric cancer cell lines: SGC-7901, AGS and MKN-28; normal gastric epithelium cell lines: GES-1 and HFE-145. There was a significant difference in FOXM1 expression between the benign and malignant gastric cell groups $(P=0.026)$. 
Table 1 Different FOXM1 expressions in gastric cancer tissues and paraneoplastic tissues

\begin{tabular}{lcccc}
\hline Variable $^{*}$ & Gastric cancer & Paraneoplastic tissues & $\mathbf{n}$ & $\mathbf{x}^{\mathbf{2}}$ \\
\hline Negative & 22 & 60 & 82 & 81.075 \\
Weakly positive & 31 & 4 & 35 & \\
Moderately positive & 38 & 3 & 41 & \\
Strongly positive & 12 & 1 & 13 & \\
Entire group & 103 & 68 & 171 & \\
\hline
\end{tabular}

Noted *: FOXM1 expression was graded according to Remmele and Halon $[27,28]$ modified by authors.

In order to explore the influence of different FOXM1 status on other independent prognostic factors, we performed a stage-stratified analysis of tumor size, $\mathrm{pT}$, and pTNM according to FOXM1 expression levels. Figure 2B showed that when the tumor size is smaller than $5 \mathrm{~cm}$, no obvious difference was observed between the survival duration in patients with different FOXM1 status. Conversely, when tumor size is larger, the five-year survival was significantly worse in those with positive FOXM1 expression than negative ones, indicating that FOXM1 expression significantly shortened the survival in patients with larger tumor size (Table 4, $\mathrm{P}=0.004$ ). Moreover, in the following analysis, the expression of FOXM1 was also found to significantly affect the survival in patients with stages T3-T4 (Table $4, \mathrm{P}=0.003$ ) or stages III-IV (Table $4, \mathrm{P}=0.001$ ), from which we can infer that at the same depth of tumor invasion or same stage, patients with FOXM1 amplifications could have a poorer survival prognosis than others (except for patients with stage T1-2 and I-II disease).

FOXM1 expression levels of cell lines and sensitivity to docetaxel

In order to explore whether there is an association between the expression of FOXM1 and chemotherapy

Table 2 Association between FOXM1 expression and clinic-pathological factors in 103 patients after gastrectomy

\begin{tabular}{|c|c|c|c|c|c|}
\hline Variable & & Entire group $(n=103)$ & FOXM1 negative & FOXM1 positive & $\mathbf{P}$ \\
\hline \multirow[t]{2}{*}{ Age } & $\leq 50$ years & 17 & 4 & 13 & 1 \\
\hline & $>50$ years & 86 & 18 & 68 & \\
\hline \multirow[t]{2}{*}{ Gender } & Male & 68 & 15 & 53 & 0.809 \\
\hline & Female & 35 & 7 & 28 & \\
\hline \multirow[t]{2}{*}{ Size } & $\leq 5 \mathrm{~cm}$ & 73 & 15 & 58 & 0.754 \\
\hline & $>5 \mathrm{~cm}$ & 30 & 7 & 23 & \\
\hline \multirow[t]{2}{*}{ Depth of tumor invasion } & $\mathrm{T} 1-2$ & 40 & 7 & 33 & 0.446 \\
\hline & T3-4 & 63 & 15 & 48 & \\
\hline \multirow[t]{2}{*}{ Lymph node metastasis } & Negative & 40 & 8 & 32 & 0.789 \\
\hline & Positive & 63 & 14 & 49 & \\
\hline \multirow[t]{2}{*}{ Degree of differentiation } & Undifferentiated & 75 & 17 & 58 & 0.596 \\
\hline & Differentiated & 28 & 5 & 23 & \\
\hline \multirow[t]{2}{*}{ Venous invasion } & Negative & 61 & 14 & 47 & 0.701 \\
\hline & Positive & 42 & 8 & 34 & \\
\hline \multirow[t]{2}{*}{ Neural invasion } & Negative & 56 & 10 & 46 & 0.344 \\
\hline & Positive & 47 & 12 & 35 & \\
\hline \multirow[t]{3}{*}{ Bomann histologic classifications $(n=77)$} & Bomannl & 4 & 1 & 3 & 0.436 \\
\hline & BomannII-III & 66 & 14 & 52 & \\
\hline & BomannIV & 7 & 3 & 4 & \\
\hline \multirow[t]{2}{*}{ TNM staging } & $|-| \mid$ & 45 & 7 & 38 & 0.206 \\
\hline & III-IV & 58 & 15 & 43 & \\
\hline \multirow[t]{3}{*}{ Lauren type } & Intestinal & 87 & 18 & 69 & 0.871 \\
\hline & Diffuse & 13 & 3 & 10 & \\
\hline & Mixed & 3 & 1 & 2 & \\
\hline
\end{tabular}

Noted $^{*}: p<0.05$ 


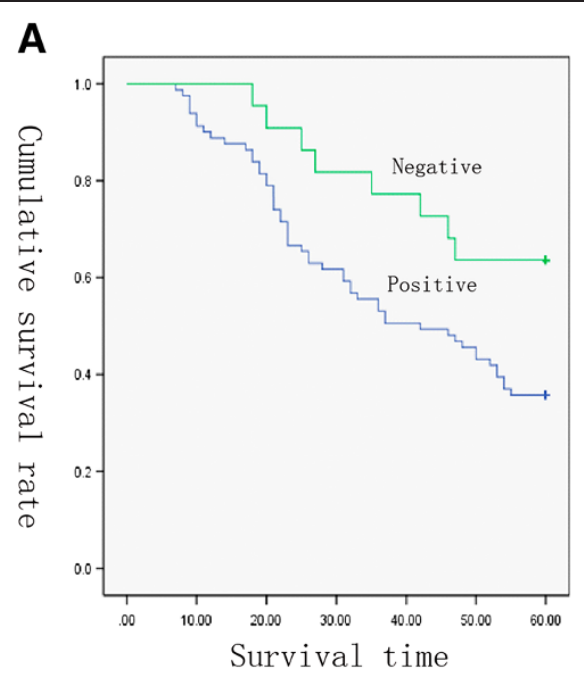

B

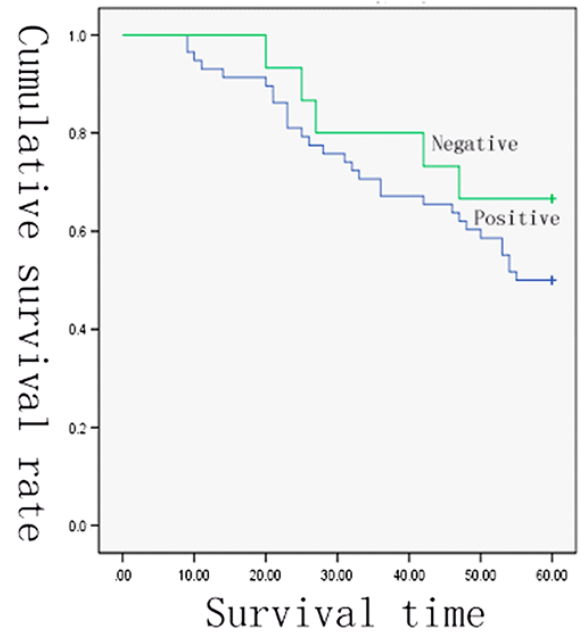

(b)

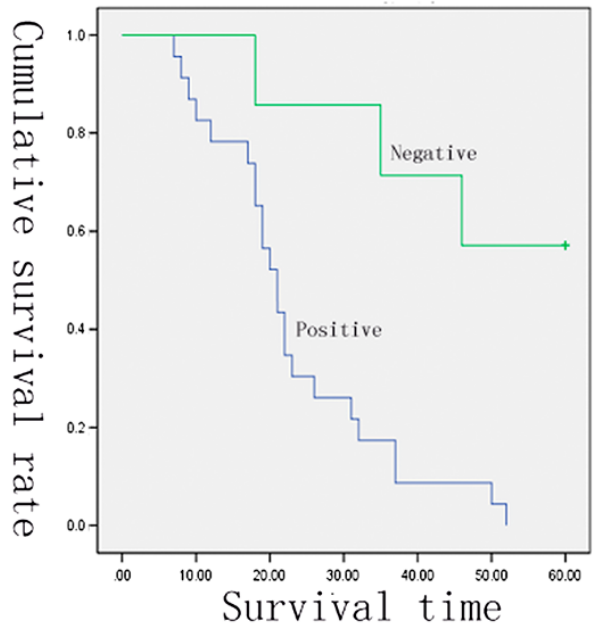

Figure 2 Kaplan-Meier survival curves for postoperational gastric cancer patients. (A) Kaplan-Meier survival curves in patients after gastrectomy according to FOXM1 expression $(n=103)(P=0.030)$. (B) Survival curves for the 103 gastric cancer patients with different tumor size according to FOXM1 expression. (a) Survival curves for the 73 patients with tumor size $\leq 5 \mathrm{~cm}$ according to FOXM1 expression ( $P=0.294)$. (b) Survival curves for the 30 patients with size of tumor $>5 \mathrm{~cm}$ according to FOXM1 expression $(P=0.004)$.

response to docetaxel, the human malignant gastric cell lines SGC-7901, AGS, and MKN-28, which has different expression levels of FOXM1, were treated with $0.02 \mathrm{mg} / \mathrm{L}$ of docetaxel for $72 \mathrm{hs}$. MTT assay was performed to test drug sensitivity. After treatment, only $15-20 \%$ of the MKN-28 cells survived, whereas the survival in FOXM1 overexpressed cells was greater than $40 \%$ (Figure 3A, P < 0.001). The IC50 of SGC-7901, AGS and MKN-28 cell lines was $0.034 \mathrm{mg} / \mathrm{L}, 0.025 \mathrm{mg} / \mathrm{L}$ and $0.016 \mathrm{mg} / \mathrm{L}$ respectively (Figure 3D left), indicating that the expression of FOXM1 correlated with docetaxel therapeutic efficacy significantly. To further confirm this result, we transfected pcDNA3.1-FOXM1 and FOXM1-siRNA into AGS cell lines (Figure 3B), and incubated them at the same drug concentration for 3 days. As shown by cell growth curve, the cell viability was absolutely lower in samples lacked FOXM1 expression, whilst the pcDNA3.1-FOXM1 transfected cells had higher viable rate (Figure $3 \mathrm{C}, \mathrm{P}<0.001$ ). Moreover, the hypothesis that knockdown of FOXM1 in AGS sensitized the cells to docetaxel treatment was also evidenced by IC50 calculations, $0.038 \mathrm{mg} / \mathrm{L}$ (pcDNA3.1FOXM1) and $0.025 \mathrm{mg} / \mathrm{L}$ (control) vs. $0.012 \mathrm{mg} / \mathrm{L}$ (siRNA FOXM1) (Figure 3D right). These data indicated that elevated FOXM1 can protect cells from docetaxol induced cell damage.

\section{Molecular evolution of gastric cancer cells lead to a} docetaxel resistant phenotype and up-regulation of FOXM1 To confirm that chemoresistance can also lead to the up-regulation of FOXM1, we established the molecular 
Table 3 Results of univariate and multivariate analysis of 5-year survival by Cox proportional hazard model

\begin{tabular}{|c|c|c|c|c|c|c|c|}
\hline \multirow[t]{2}{*}{ Variable } & \multirow[b]{2}{*}{$\mathbf{n}$} & \multicolumn{3}{|c|}{ Univariate analysis } & \multicolumn{3}{|c|}{ Multivariate analysis } \\
\hline & & OR & $95.0 \% \mathrm{Cl}$ & $\mathbf{P}$ & OR & $95.0 \% \mathrm{Cl}$ & $\mathbf{P}$ \\
\hline Age ( $\leq 50$ years / >50 years) & $19 / 84$ & 0.738 & $0.363-1.499$ & 0.4 & & & \\
\hline Gender (F/M) & $68 / 35$ & 0.759 & $0.440-1.308$ & 0.32 & & & \\
\hline Size of tumor $(\leq 5 \mathrm{~cm} />5 \mathrm{~cm})$ & $73 / 30$ & 0.287 & $0.170-0.483$ & $0.001^{* *}$ & 0.532 & $0.306-0.925$ & $0.025^{*}$ \\
\hline Depth of tumor invasion (T1-2/T3-4) & $40 / 63$ & 0.209 & $0.108-0.404$ & $0.002^{* *}$ & 7.798 & $1.993-14.561$ & $0.009^{* *}$ \\
\hline Lymph node metastatis (negative/positive) & $40 / 63$ & 0.179 & $0.090-0.355$ & $0.002^{* *}$ & 0.457 & $0.192-1.086$ & 0.076 \\
\hline Degree of differentiation (undifferentiated/differentiated) & $75 / 28$ & 1.041 & $0.593-1.825$ & 0.889 & & & \\
\hline Venous invasion (negative/positive) & $61 / 42$ & 0.375 & $0.225-0.628$ & $0.001^{* *}$ & 0.758 & $0.433-1.326$ & 0.332 \\
\hline Neural invasion (negative/positive) & $56 / 47$ & 0.917 & $0.553-1.523$ & 0.739 & & & \\
\hline FOXM1 expession (negative/positive) & $22 / 81$ & 2.277 & $1.081-4.796$ & $0.030^{*}$ & 6.251 & $2.699-14.478$ & $0.001^{* *}$ \\
\hline TNM staging (I-II/III-IV) & $45 / 58$ & 0.118 & $0.059-0.237$ & $<0.001^{* *}$ & 0.012 & $0.001-0.099$ & $<0.001^{* *}$ \\
\hline Lauren type (intestinal/diffuse and mixed) & $87 / 16$ & 0.700 & $0.318-1.541$ & 0.376 & & & \\
\hline
\end{tabular}

Noted $^{*}: p<0.05 ;{ }^{* *}: p<0.01$.

evolution assay, where the malignant human gastric cell line AGS was treated with docetaxel for several cycles. After each treatment round, cells were harvested for MTT assays as well as RNA and protein isolation to investigate chemosensitivity changes and gene expressions. As a result, MTT assays revealed that cells in sequential treatment cycles had increasing IC50 calculations (Figure 4A), demonstrating that the resistance to docetaxel rose especially from the fourth treatment cycle on. In addition, changes in the levels of FOXM1 could be observed simultaneously. PCR result showed that the level of FOXM1 was significantly up-regulated after the fourth treated round (Figure 4B, P <0.05), while the expression of FOXM1 altered correspondingly with mRNA levels (Figure $4 \mathrm{C}, \mathrm{P}<0.05$ ). Based on such treatment cycle, AGS cells were finally succeed to have a good tolerance of docetaxel to the concentration of $0.2 \mathrm{mg} / \mathrm{L}$, and were regarded as the AGS-DOC ${ }^{\mathrm{R}}$ cell lines. These results provided another aspect of evidence and fully proved that FOXM1 could mediate the therapeutic resistance to docetaxel in gastric cancer.

Table 4 Results of tumor size, pT, and pTNM stagestratified analysis according to FOXM1 expression

\begin{tabular}{cccc}
\hline Variable & OR & $\mathbf{9 5 . 0 \% ~ C l}$ & $\mathbf{P}$ \\
\hline T1-2 & 1.032 & $0.223-4.777$ & 0.968 \\
T3-4 & 3.758 & $1.589-8.886$ & $0.003^{*}$ \\
$\mathbf{5} \mathbf{~ c m}$ & 1.662 & $0.643-4.294$ & 0.294 \\
$>\mathbf{5} \mathbf{~ c m}$ & 6.206 & $1.784-21.59$ & $0.004^{*}$ \\
I-II & 6.986 & $0.023-12.203$ & 0.362 \\
III-IV & 3.901 & $1.800-8.457$ & $0.001^{*}$ \\
\hline Noted ${ }^{*}: \mathbf{p}<0.01$. & & &
\end{tabular}

FOXM1 confers resistance to docetaxel by altering microtubule dynamics in preventing docetaxel induced apoptosis

Several mechanisms to combat palitaxol induced apoptosis have been reported previously. Namely, upregulation of MDR1 (multi-drug resistant protein 1), a P-Glycoprotein family member can shuttle toxins out of cells; up-regulation of the CIAP (inhibitors of apoptosis) family members including Survivin; and the altered microtubule dynamics [29]. Given the overlapping roles of docetaxel and FOXM1 upon affecting the microtubule dynamics of mitosis progression in tumor cells, we suggested hypothesis that altered microtubule dynamics mediated by FOXM1 could prevent docetaxol induced apoptosis, which caused docetaxel resistance in gastric cancers.

To examine its possibility, we compared the ratio of soluble to polymerized microtubule fractions after docetaxel treatment. Cell lysates were fractionated to obtain polymerized and soluble tubulin fractions in FOXM1-siRNA transfected and FOXM1 overexpressed gastric cell lines that were left untreated or treated with docetaxol. Without drug treatment, cells showed similar tubulin ratios and most of the detectable tubulins were in the soluble form. Upon treatment with docetaxol, FOXM1 knockdown cells showed a dramatic shift towards the polymerized fraction. The FOXM1 expressing cells did show a shift towards the polymerized fraction but the ratio was significantly lower (Figure 5, P $<0.01$ ). These data clearly indicated that through interfering in microtubule polymerization, the antitumor activity of docetaxel was inhibited by FOXM1 overexpression in gastric cancer cells, actually testifying our previous hypothesis. 
A

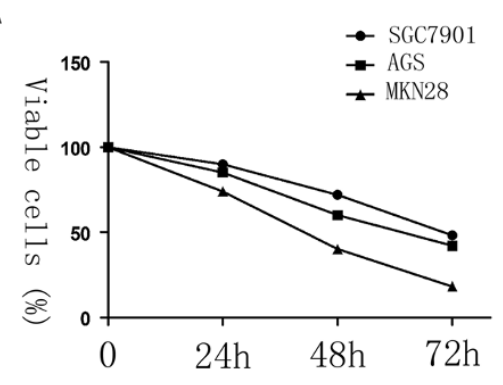

B

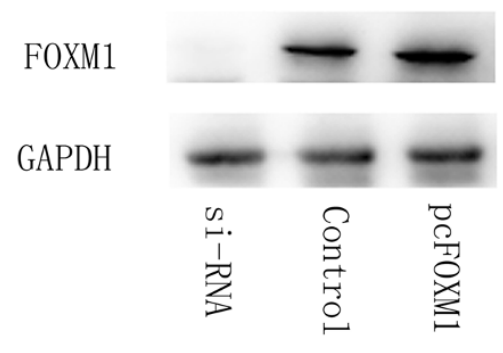

C

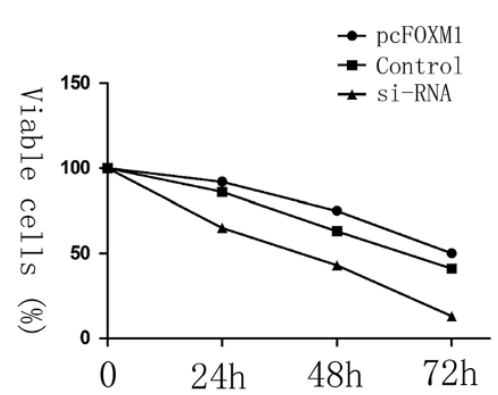

D

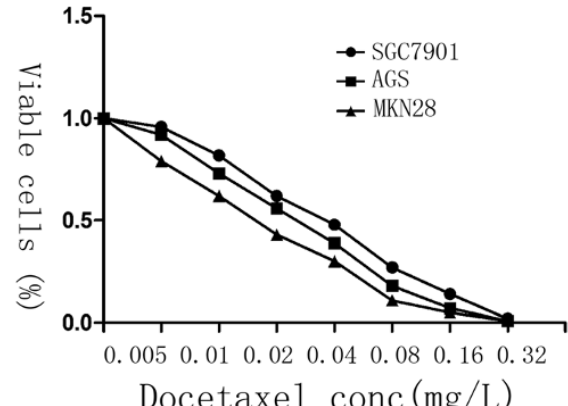

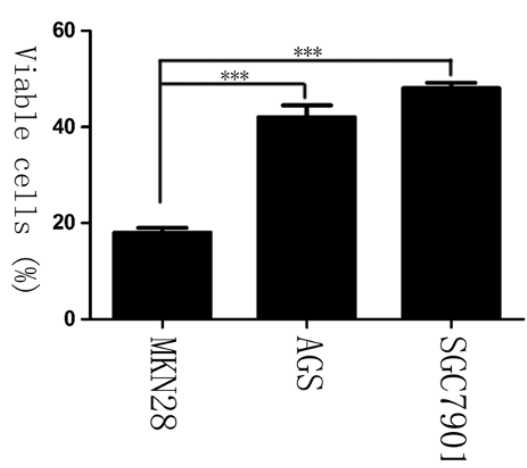
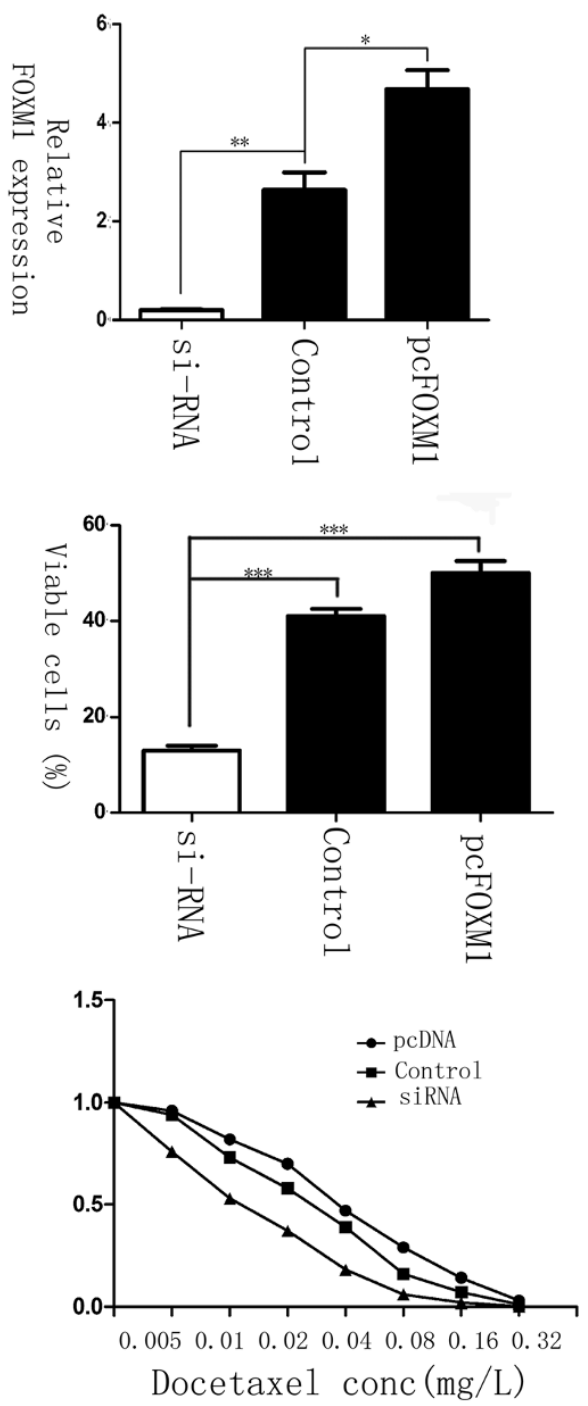

Figure 3 Elevated levels of FOXM1 correlate with resistance to docetaxel in gastric cancer. (A) AGS, SGC-7901 and MKN-28 cells were treated with $0.02 \mathrm{mg} / \mathrm{L}$ of docetaxel for $0,24,48$ and $72 \mathrm{~h}$. MTT assay was performed to test the cell viability. The IC50 calculations in the three cell lines were $0.034 \mathrm{mg} / \mathrm{L}, 0.025 \mathrm{mg} / \mathrm{L}$ and $0.016 \mathrm{mg} / \mathrm{L}$ separately (D left). (B) The expression of FOXM1 in AGS cell lines with the transfection of FOXM1-siRNA, pcDNA3,1 or pcDNA3, 1-FOXM1, analyzed by western blot $48 \mathrm{~h}$ later. (C) Gastric cell lines AGS were treated with docetaxel at the concentration of $0.02 \mathrm{mg} / \mathrm{L}$ after FOXM1-siRNA or pcDNA3, 1-FOXM1 transfection. Cell growth curves were drawn by MTT assays. The IC50 in FOXM1 knockdown, overexpressed and control groups was $0.012 \mathrm{mg} / \mathrm{L}, 0.025 \mathrm{mg} / \mathrm{L}$ and $0.038 \mathrm{mg} / \mathrm{L}$ respectively (D right). ${ }^{*}, P \leq 0.05 ;{ }^{* *}, P \leq 0.01$; ***, $P \leq 0.001$ significant. 

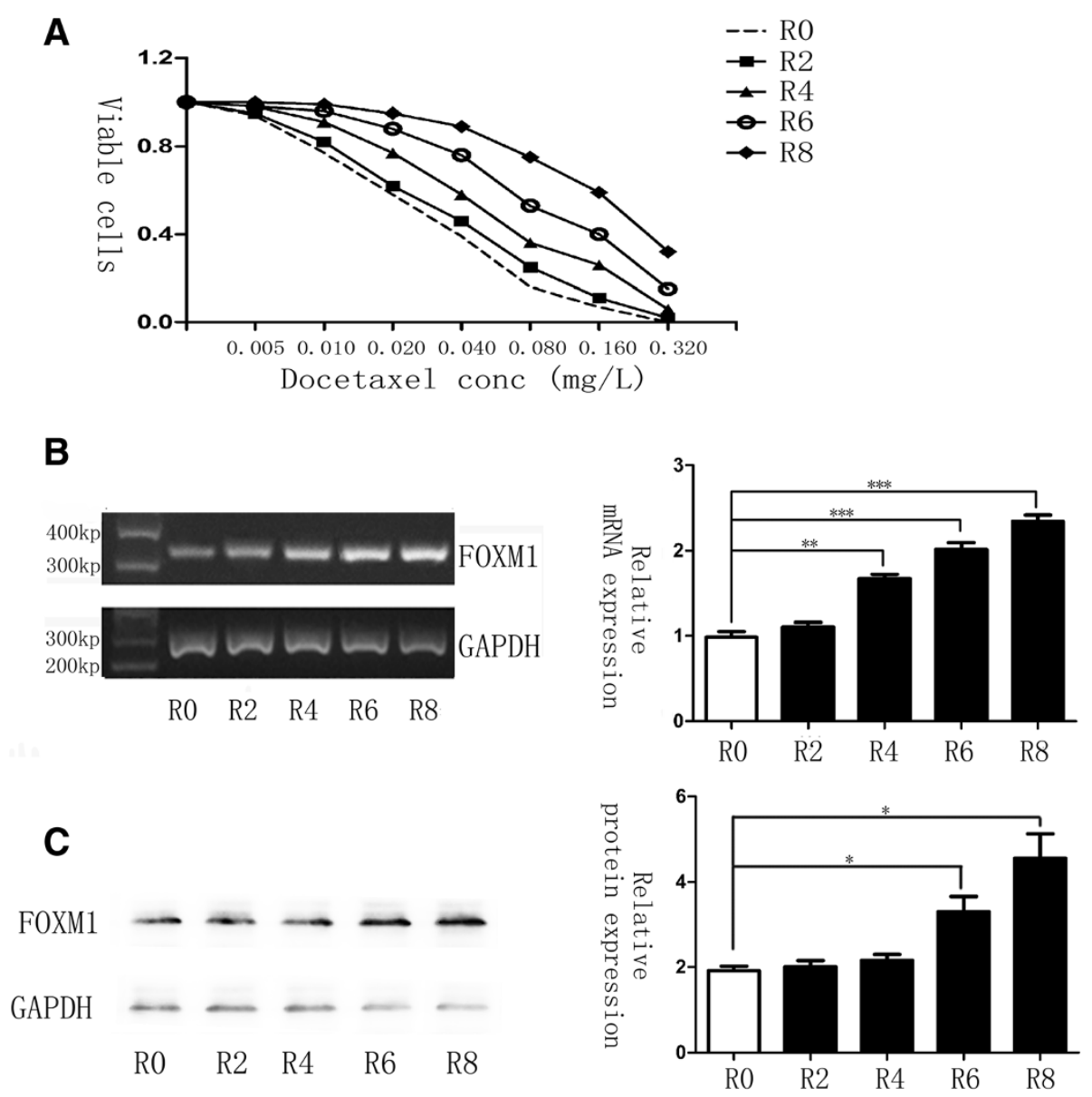

Figure 4 Docetaxel resistant cell line shows elevated FOXM1 mRNA and protein expression levels. (A) Cells in different cycle of molecular evolution assay were treated with docetaxel respectively, and their rates of cell viability were measured by MTT assay. R0 represents the untreated control cell line, whereas R2, R4, R6 and R8 represents AGS cells that are treated with $0.02 \mathrm{mg} / \mathrm{L}$ docetaxel for two, four, six and eight times, separately. IC50 for cells in R0, R2, R4, R6 and R8 was 0.026, 0.033, 0.054, 0.098, 0.190 mg/L. (B) FOXM1 mRNA transcript levels in R0, R2, R4, R6 and R8 cells were determined by RT-PCR analysis. (C) Western blot analysis was performed to detect the relative protein expression levels of FOXM1 in the different treated round. Statistical analysis was performed using Student's t tests. ${ }^{*}, P \leq 0.05 ;{ }^{* *}, P \leq 0.01 ;{ }^{* *}, P \leq 0.001$ significant.

Thiostrepton can overcome docetaxel resistance in gastric cancer cells through down-regulation of FOXM1

To test if FOXM1 inactivation is a viable strategy for overcoming docetaxel resistance, we studied the effects of AGS$\mathrm{DOC}^{\mathrm{R}}$ cells treated with FOXM1 inhibitor thiostrepton [30]. In result, MTT assays revealed that docetaxel resistant cells exhibited a significant reduction in the rate of cell viability after treated with thiostrepton or in combination with docetaxel compared with the single treatment of docetaxel. 72 hours later, drug resistant cells treated with thiostrepton alone showed a 59\% cell survival rate, whilst the combination of docetaxel and thiostrepton indicated a synergy, exhibiting a cell survival rate of $34 \%$ in this experiment (Figure 6A). Moreover, in drug resistant cells treated with thiostrepton or thiostrepton and docetaxel, the downregulation of FOXM1 occurred at $48 \mathrm{~h}$ and $24 \mathrm{~h}$ following treatment respectively (Figure 6B). The shorter time needed for FOXM1 down-regulation in the co-treated cells may reflect the higher levels of cell death happened when both drugs were administered together. Taken together, shown by our research, the resistance of docetaxel is able to be reversed in gastric cancer cells through the inhibition of FOXM1.

\section{Discussion}

In current study, we demonstrated that the level of FOXM1 expression was significantly higher in gastric cancer than in para-cancer tissues and normal gastric cell lines. Although no significant association was found between FOXM1 expression and any clinical pathological features, FOXM1 amplification was identified as an independent prognostic factor in gastric cancer, and its affection is more significant in patients with advanced stage. Moreover, shown to mediate docetaxel resistance in gastric cancers, FOXM1 was revealed to interfere in microtubule polymerization after the treatment of docetaxel in 


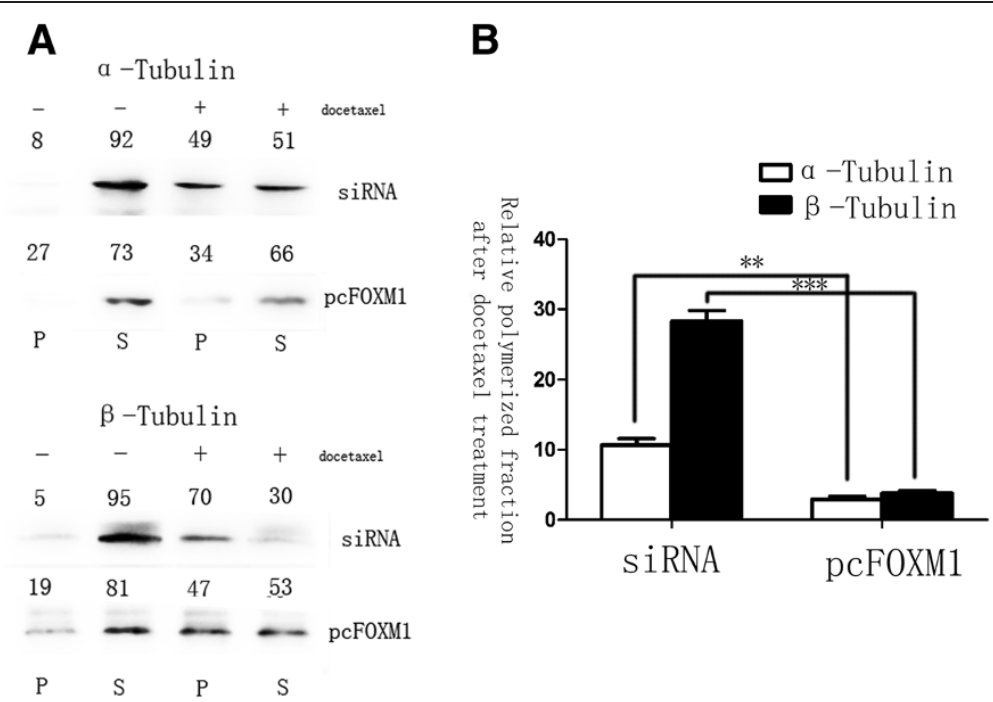

Figure 5 FOXM1 alters the microtubule dynamics in preventing docetaxel induced apoptosis. Polymerized and soluble tubulin fractions from docetaxel untreated and treated FOXM1-siRNA and pcDNA3, 1-FOXM1 transfected cell lines were generated by centrifugation. Western blot was used to assay a-tubulin and $\beta$-tubulin ratios in polymerized and soluble fractions. (A) Relative percentages are shown above western blot. (B) The soluble to polymerized microtubule fractions after docetaxel treatment were significantly inhibited in FOXM1 overexpressed group, analyzed by $t$ test both for $a$-tubulin and $\beta$-tubulin. ${ }^{* *}, P \leq 0.01 ;{ }^{* *}, P \leq 0.001$ significant.

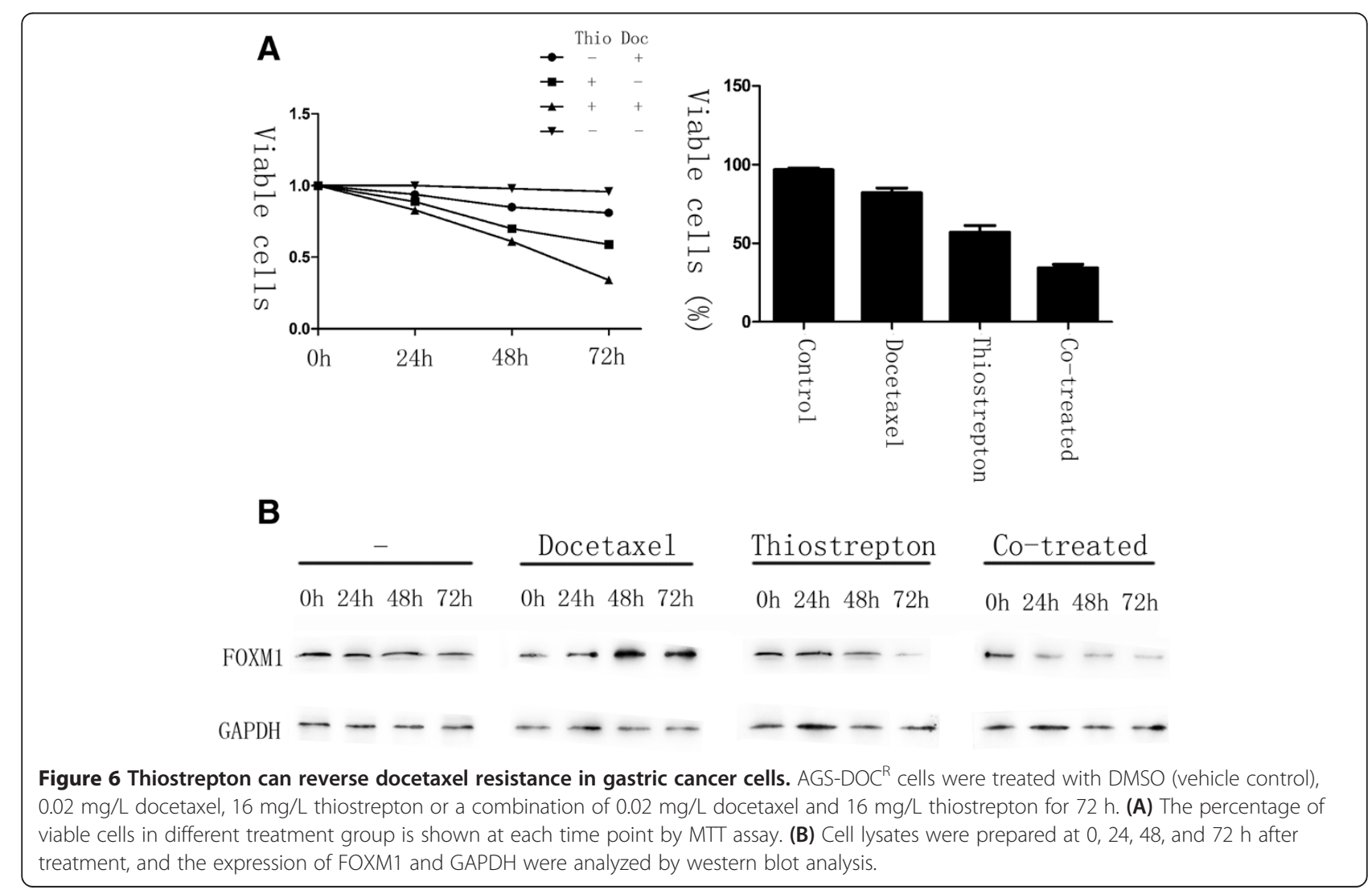


our research. When we attenuated FOXM1 expression with FOXM1 inhibitor thiostrepton, docetaxel resistance in gastric cancers could be reversed, simultaneously with the down-regulation of FOXM1.

Forkhead transcription factor is a new family of transcription factors, which was officially unified in 2000 [31]. In previous studies, FOXM1 was revealed to promote cell cycle by directly activating its downstream genes $[19,20]$. Furthermore, the overexpressed FOXM1 could simultaneously induce gastric cancer angiogenesis and progression through regulating the level of VEGF (vascular endothelial growth factor) gene expression and correlating with MVD (microvessel density) [26]. These researches may explain why no association was found between FOXM1 expression and clinical pathological parameters, for the clinical features such as tumor size, depth of invasion and lymph node metastasis cannot fully represent the proliferation activity of the tumor cells, whereas FOXM1 mainly reflected the division of cells. This result was agreed with Kaoru Okada's study, which also detected the expression of FOXM1 in gastric cancer and showed the positive expression did not correlate with any clinic-pathological features [23]. Moreover, overexpression of FOXM1 was previously reported to contribute to the elevated migratory and invasive abilities in oral cavity squamous cell carcinoma [32], indicating that FOXM1 was associated with an aggressive behavior of tumor cells in vitro. These hypotheses were further provided by our results, which showed that FOXM1 is an independent prognostic factor in gastric cancer. Additionally, in order to address the confound influence of other independent prognostic factors, we performed the size, pT and pTNM stratified analysis according to FOXM1 expression levels. As a result, the prognosis was significantly poorer for patients with positive FOXM1 expression when limited to the same tumor size $(>5 \mathrm{~cm})$, depth of invasion (T3 and T4) or TNM stage (III-IV), whilst no significant relationship was found between FOXM1 expression and survival duration for patients with stage T1-2, I-II and smaller tumor size. It can be speculated that some other factor may be more significant than FOXM1 in predicting the prognosis at early stage, such as lymph node metastasis [33], whereas in advanced stage, angiogenesis, which is promoted by FOXM1, may influence the growth velocity of tumor more significantly [26]. Based on these results, it is considerately that FOXM1 should be combined with the tumor size, T stage and TNM stage for predicting the prognosis of gastric cancer, and further studies should focus on exploring the mechanism of FOXM1 on promoting the adverse progression of advanced gastric cancers.

In gastric cancer treatment, classical chemotherapy is largely used besides surgery operation, radiotherapy and novel targeted therapy approaches. For instance, docetaxel is commonly used as single-agent or in combination with other drugs like platinum and fluoropyrimidine (DCF regimen) in a neo-adjuvant or advanced stage setting [34,35]. The chemotherapy based on docetaxel may be effective, because docetaxel was reported to lack cross-resistance with other anti-tumor drugs [4]. However, the resistance to docetaxel did occur and FOXM1 was shown to be a critical molecular for that resistance in gastric cancer by our current research, for which elevated levels of FOXM1 was shown to correlate with lower drug susceptibility, whilst the molecular evolution assay of AGS resulted in significantly more resistant cells possessed FOXM1 overexpression. Additionally, Carr et al. have reported that FOXM1 functioned chemoresistance to a microtubule stabilizing anticancer drug, paclitaxel by directly regulating the microtubule destabilizing protein Stathmin and altering dynamics of microtubule in breast cancer [25]. As docetaxel is also an anticancer agent, which binds to $\beta$ tubulin and stabilizes microtubules consisting $\alpha / \beta$-tubulin dimers, resulting in mitotic failure like paclitaxel, the same mechanism should occur in gastric cancer cells. Accordingly, through tubulin assay analysis, we found that microtubules in FOXM1 overexpressed cell lines fail to polymerize in response to docetaxol treatment, indicating that FOXM1 did prevent docetaxol induced apoptosis by altering the microtubule dynamics in gastric cancer, however, the downstream genes of FOXM1 was not revealed by our research yet. Moreover, after treated cells with FOXM1 inhibitor thiostrepton, the acquired drug resistance was reversed with the down-regulation of FOXM1 expression, demonstrating the inactivation of FOXM1 was essential for reversing docetaxel resistance and targeting FOXM1 could potentially be a better therapeutic strategy for overcoming the resistance to docetaxel. Nevertheless, this inhibitory effect on FOXM1 has not been analyzed for human gastric cancer so far. Therefore, further studies should be focused on the anti-tumor function of FOXM1 inhibitors, especially in docetaxel-resistant gastric cancer.

\section{Conclusion}

In conclusion, our study showed that FOXM1 was an independent prognostic factor for gastric cancer patients. Further, we also showed that FOXM1 is a critical mediator of docetaxel sensitivity and resistance in gastric cancer cells. Therefore, FOXM1 can be a useful marker for predicting patients' prognosis and monitoring docetaxel response, which might be a new therapeutic target in docetaxel resistant gastric cancer.

\section{Abbreviations}

FOXM1: Forkhead box transcription factor 1; DCF: Chemotherapy regimen of docetaxel cisplatin and 5-fluorouracil; NSCLC: Non-small cell lung cancer; AJCC: The 7th American Joint Committee on Cancer; DMSO: Dimethyl 
sulfoxide; IHC: Immunohistochemistry; MDR1: Multi-drug resistant protein 1; VEGF: Vascular endothelial growth factor; MVD: Micro vessel density.

\section{Competing interests}

The authors declare that they have no competing interests.

\section{Authors' contributions}

$X L, W Q$, and $R Y$ designed the experiment. $X L, B L, S L$ and $Y Y$ performed the experiments. WQ correlated the data and interpreted results. BL performed the statistical analysis. XL drafted manuscript. WQ, RY and SL made critical revision to manuscript. JL was general supervisor of the study, with contribution to the conception and design of the study, as well as data analysis. All authors have read and approved the final manuscript.

\section{Acknowledgements}

This study is supported by the grant of Medicine and healthy technology development program of Shandong province (2011HZO28).

\section{Author details}

'Department of Oncology, Affiliated Hospital of Medical College Qingdao University, 16 Jiangsu Road, Qingdao 266003, China. ${ }^{2}$ Department of Nuclear Medicine, Affiliated Hospital of Medical College Qingdao University, Qingdao, China. ${ }^{3}$ Central Laboratory, Affiliated Hospital of Medical College Qingdao University, Qingdao, China.

Received: 19 June 2013 Accepted: 2 September 2013

Published: 3 September 2013

\section{References}

1. Chen W, Zheng R, Zhang S, Zhao P, Li G, Wu L, He J: The incidences and mortalities of major cancers in China, 2009. Chin J Cancer 2013, 32:106-112.

2. Ohtsu A: Chemotherapy for metastatic gastric cancer: past, present, and future. J Gastroenterol 2008, 43:256-264.

3. Fumoleau P, Perrocheau G, Maugard-Louboutin C, Lemevel B: Paclitaxel (Taxol) and docetaxel (Taxotere): results of phase II trials in monochemotherapy. Bull Cancer 1995, 82:629-636.

4. Haller DG, Misset JL: Docetaxel in advanced gastric cancer. Anticancer Drugs 2002, 13:451-460.

5. Giuliani F, Gebbia V, De Vita F, Maiello E, Di Bisceglie M, Catalano G, Gebbia $\mathrm{N}$, Colucci G: Docetaxel as salvage therapy in advanced gastric cancer: a phase II study of the Gruppo Oncologico Italia Meridionale (G.O.I.M.). Anticancer Res 2003, 23:4219-4222.

6. Chen XZ, Jiang K, Hu JK, Zhang B, Gou HF, Yang K, Chen ZX, Chen JP: Costeffectiveness analysis of chemotherapy for advanced gastric cancer in China. World J Gastroenterol 2008, 14:2715-2722.

7. Ajani JA: Docetaxel for gastric and esophageal carcinomas. Oncol (Williston Park) 2002, 16:89-96.

8. Oh DY, Kim TY, Kwon JH, Lee JJ, Joh Y, Kim DW, Heo DS, Bang YJ, Kim NK: Docetaxel + 5-fluorouracil + cisplatin 3-day combination chemotherapy as a first-line treatment in patients with unresectable gastric cancer. Jpn J Clin Oncol 2005, 35:380-385.

9. Oh SC, Park KH, Choi IK, Yoon SY, Kim SJ, Seo JH, Choi CW, Kim BS, Shin SW, Kim JS, Kim YH: Docetaxel (Taxotere), cisplatin, UFT, and leucovorin combination chemotherapy in advanced gastric cancer. Br J Cancer 2005, 92:827-831.

10. Park SR, Chun JH, Kim YW, Lee JH, Choi IJ, Kim CG, Lee JS, Bae JM, Kim HK: Phase II study of low-dose docetaxel/fluorouracil/cisplatin in metastatic gastric carcinoma. Am J Clin Oncol 2005, 28:433-438.

11. Lorenzen S, Hentrich M, Haberl C, Heinemann V, Schuster T, Seroneit T, Roethling N, Peschel C, Lordick F: Split-dose docetaxel, cisplatin and leucovorin/fluorouracil as first-line therapy in advanced gastric cancer and adenocarcinoma of the gastroesophageal junction: results of a phase II trial. Ann Oncol 2007, 18:1673-1679.

12. Ajani JA, Moiseyenko VM, Tjulandin S, Majlis A, Constenla M, Boni C, Rodrigues A, Fodor M, Chao Y, Voznyi E, et al: Clinical benefit with docetaxel plus fluorouracil and cisplatin compared with cisplatin and fluorouracil in a phase III trial of advanced gastric or gastroesophageal cancer adenocarcinoma: the V-325 Study Group. J Clin Oncol 2007, 25:3205-3209.
13. Ajani JA, Moiseyenko VM, Tjulandin S, Majlis A, Constenla M, Boni C, Rodrigues A, Fodor M, Chao Y, Voznyi E, et al: Quality of life with docetaxel plus cisplatin and fluorouracil compared with cisplatin and fluorouracil from a phase III trial for advanced gastric or gastroesophageal adenocarcinoma: the V-325 Study Group. J Clin Oncol 2007, 25:3210-3216.

14. Sadighi S, Mohagheghi MA, Montazeri A, Sadighi Z: Quality of life in patients with advanced gastric cancer: a randomized trial comparing docetaxel, cisplatin, 5-FU (TCF) with epirubicin, cisplatin, 5-FU (ECF). BMC Cancer 2006, 6:274.

15. Suzuki T, Yoshida K, Wada Y, Hamai Y, Sentani K, Oue N, Yasui W: Melanoma-associated antigen-A1 expression predicts resistance to docetaxel and paclitaxel in advanced and recurrent gastric cancer. Oncol Rep 2007, 18:329-336.

16. Wierstra I, Alves J: FOXM1, a typical proliferation-associated transcription factor. Biol Chem 2007, 388:1257-1274.

17. Ma RY, Tong TH, Leung WY, Yao KM: Raf/MEK/MAPK signaling stimulates the nuclear translocation and transactivating activity of FOXM1. Methods Mol Biol 2010, 647:113-123.

18. Katoh $Y$, Katoh M: Hedgehog target genes: mechanisms of carcinogenesis induced by aberrant hedgehog signaling activation. Curr Mol Med 2009, 9:873-886.

19. Wang IC, Chen YJ, Hughes D, Petrovic V, Major ML, Park HJ, Tan Y, Ackerson $\mathrm{T}$, Costa RH: Forkhead box M1 regulates the transcriptional network of genes essential for mitotic progression and genes encoding the SCF (Skp2-Cks1) ubiquitin ligase. Mol Cell Biol 2005, 25:10875-10894.

20. Costa RH: FoxM1 dances with mitosis. Nat Cell Biol 2005, 7:108-110.

21. Liu M, Dai B, Kang SH, Ban K, Huang FJ, Lang FF, Aldape KD, Xie TX, Pelloski $\mathrm{CE}$, Xie $\mathrm{K}$, et al: FoxM1B is overexpressed in human glioblastomas and critically regulates the tumorigenicity of glioma cells. Cancer Res 2006, 66:3593-3602.

22. Yau C, Wang Y, Zhang Y, Foekens JA, Benz CC: Young age, increased tumor proliferation and FOXM1 expression predict early metastatic relapse only for endocrine-dependent breast cancers. Breast Cancer Res Treat 2011, 126:803-810.

23. Okada K, Fujiwara Y, Takahashi T, Nakamura Y, Takiguchi S, Nakajima K, Miyata H, Yamasaki M, Kurokawa Y, Mori M, Doki Y: Overexpression of forkhead box M1 transcription factor (FOXM1) is a potential prognostic marker and enhances chemoresistance for docetaxel in gastric cancer. Ann Surg Oncol 2013, 20:1035-1043.

24. Xu N, Zhang X, Wang X, Ge HY, Wang XY, Garfield D, Yang P, Song YL, Bai CX: FoxM1 mediated resistance to gefitinib in non-small-cell lung cancer cells. Acta Pharmacol Sin 2012, 33:675-681.

25. Carr JR, Park HJ, Wang Z, Kiefer MM, Raychaudhuri P: FoxM1 mediates resistance to herceptin and paclitaxel. Cancer Res 2010, 70:5054-5063.

26. Li Q, Zhang N, Jia Z, Le X, Dai B, Wei D, Huang S, Tan D, Xie K: Critical role and regulation of transcription factor FoxM1 in human gastric cancer angiogenesis and progression. Cancer Res 2009, 69:3501-3509.

27. Remmele W, Stegner HE: Recommendation for uniform definition of an immunoreactive score (IRS) for immunohistochemical estrogen receptor detection (ER-ICA) in breast cancer tissue. Pathologe 1987, 8:138-140.

28. Halon A, Donizy P, Biecek P, Rudno-Rudzinska J, Kielan W, Matkowski R: HER-2 expression in immunohistochemistry has no prognostic significance in gastric cancer patients. ScientificWorldJournal 2012, 2012:941259.

29. Orr GA, Verdier-Pinard P, McDaid H, Horwitz SB: Mechanisms of Taxol resistance related to microtubules. Oncogene 2003, 22:7280-7295.

30. Kwok JM, Myatt SS, Marson CM, Coombes RC, Constantinidou D, Lam EW: Thiostrepton selectively targets breast cancer cells through inhibition of forkhead box M1 expression. Mol Cancer Ther 2008, 7:2022-2032.

31. Kaestner $\mathrm{KH}$, Knochel W, Martinez DE: Unified nomenclature for the winged helix/forkhead transcription factors. Genes Dev 2000, 14:142-146.

32. Chen $\mathrm{CH}$, Chien CY, Huang CC, Hwang CF, Chuang HC, Fang FM, Huang HY, Chen CM, Liu HL, Huang CY: Expression of FLJ10540 is correlated with aggressiveness of oral cavity squamous cell carcinoma by stimulating cell migration and invasion through increased FOXM1 and MMP-2 activity. Oncogene 2009, 28:2723-2737.

33. Zu H, Wang F, Ma Y, Xue Y: Stage-stratified analysis of prognostic significance of tumor size in patients with gastric cancer. PLOS One 2013, 8:e54502.

34. Tebbutt NC, Cummins MM, Sourjina T, Strickland A, Van Hazel G, Ganju V, Gibbs D, Stockler M, Gebski V, Zalcberg J: Randomised, non-comparative 
phase II study of weekly docetaxel with cisplatin and 5-fluorouracil or with capecitabine in oesophagogastric cancer: the AGITG ATTAX trial. Br J Cancer 2010, 102:475-481.

35. Van Cutsem E, Moiseyenko VM, Tjulandin S, Majlis A, Constenla M, Boni C, Rodrigues A, Fodor M, Chao Y, Voznyi E, et al: Phase III study of docetaxel and cisplatin plus fluorouracil compared with cisplatin and fluorouracil as first-line therapy for advanced gastric cancer: a report of the V325 Study Group. J Clin Oncol 2006, 24:4991-4997.

doi:10.1186/1479-5876-11-204

Cite this article as: Li et al.: Forkhead box transcription factor 1 expression in gastric cancer: FOXM1 is a poor prognostic factor and mediates resistance to docetaxel. Journal of Translational Medicine 2013 11:204.

\section{Submit your next manuscript to BioMed Central and take full advantage of:}

- Convenient online submission

- Thorough peer review

- No space constraints or color figure charges

- Immediate publication on acceptance

- Inclusion in PubMed, CAS, Scopus and Google Scholar

- Research which is freely available for redistribution 